\title{
Image Processing of Radar Mosaics for the Climatology of Convection Initiation in South China
}

\author{
LANQIANG BAI AND GUIXING CHEN \\ School of Atmospheric Sciences, and Guangdong Province Key Laboratory for Climate Change and Natural Disaster Studies, \\ Sun Yat-sen University, Guangzhou, and Southern Marine Science and Engineering Guangdong Laboratory (Zhuhai), Zhuhai, China \\ LING HUANG \\ Institute of Tropical and Marine Meteorology, China Meteorological Administration, Guangzhou, China
}

(Manuscript received 5 April 2019, in final form 1 November 2019)

\begin{abstract}
A dataset of convection initiation (CI) is of great value in studying the triggering mechanisms of deep moist convection and evaluating the performances of numerical models. In recent years, the data quality of the operationally generated radar mosaics over China has been greatly improved, which provides an opportunity to retrieve a CI dataset from that region. In this work, an attempt is made to reveal the potential of applying a simple framework of objective CI detection for the study of CI climatology in China. The framework was tested using radar mosaic maps in South China that were accessible online. The identified CI events were validated in both direct and indirect ways. On the basis of a direct manual check, nearly all of the identified CI cells had an organized motion. The precipitation echoes of the cells had a median duration of approximately $2.5 \mathrm{~h}$. The CI occurrences were further compared with rainfall estimates to ensure physical consistency. The diurnal cycle of CI occurrence exhibits three major modes: a late-night-to-morning peak at the windward coasts and offshore, a noon-to-late-afternoon peak on the coastal land, and an evening-to-early-morning peak over the northwestern highland. These spatial modes agree well with those of rainfall, indirectly suggesting the reliability of the CI statistics. By processing radar mosaic maps, such a framework could be applied for studying CI climatology over China and other regions.
\end{abstract}

\section{Introduction}

Deep moist convection often induces severe weather, such as intense rainfall, strong winds, hail, lightning, and tornadoes. The initial formation of deep moist convection is generally termed convection initiation (CI). Predicting CI is of particular interest to forecasters because of its close association with the subsequent intensified convection and severe weather (Markowski et al. 2006). So far, it is truly challenging to skillfully predict exactly when and where a convective storm will develop (e.g., Ziegler and Rasmussen 1998; Lock and Houston 2014; Bai et al. 2019; Weckwerth et al. 2019). Improving our understanding of CI and the representation of CI in convection-permitting models are helpful for predicting hazardous weather.

Previous studies have suggested that the statistical analysis of regional CI events is an important approach

Corresponding author: Dr. Guixing Chen, chenguixing@ mail.sysu.edu.cn to reveal the processes that control convective growth. By detecting the CI events in the U.S. Rocky Mountains, Banta and Schaaf (1987) identified some topographic features with a high likelihood of initiating convection. They summarized several CI mechanisms over the mountains, such as orographic lifting, leeside convergence, channeling and wake effects. The identified CI-prone zones were active under certain wind regions, which may help the regional CI nowcasting. From a 9-yr CI dataset over a complex topography in Europe, Weckwerth et al. (2011) also found that the CI preferentially occurred over the local higher terrains such as mountain slopes or peaks. In addition to topography, the convergent boundaries in the planetary boundary layer are often recognized as the precursors to CI, particularly over a relatively flat underlying surface (Purdom 1976; Wilson and Schreiber 1986; Weckwerth and Parsons 2006). For instance, a 20 -yr climatology of nocturnal CI over the central and southern Great Plains suggests that approximately $76 \%$ of the CI events occur near surface 
boundaries (Reif and Bluestein 2017). There is also a high percentage of nocturnal CI events associated with lowlevel jets (LLJs), suggesting that LLJs may play a role in initiating nocturnal convection. These studies indicate that long-period statistics of CI may help to clarify the specific topography and atmospheric processes that repeatedly trigger convection. The CI statistics can also be used to evaluate the convection-permitting NWP models (Keat et al. 2019) and to design the intensive observation networks for convective systems (Nakatani et al. 2015).

The increasing availability and temporal length of remotely sensed dataset (e.g., radar data) provide the possibility of building long-term CI datasets and studying CI climatology. Doppler weather radars have the ability to detect convection-related hydrometeors at high spatial and temporal resolutions on orders of $\sim 10^{2} \mathrm{~m}$ and $\sim 10^{\circ} \mathrm{min}$, respectively. Thus, the radar dataset is suitable for the study of CI climatology, given that the time scale required to grow precipitation-size hydrometeors in deep convective circulations is $\sim 30 \mathrm{~min}$ (Knight and Squires 1982). To overcome the limited coverage of one single Doppler radar, the usage of mosaics from multiple radars is increasingly employed in climate studies of CI (e.g., M. Chen et al. 2012; Y. Wang et al. 2014; Fabry et al. 2013, 2017; Reif and Bluestein 2017; Huang et al. 2017). In particular, Fabry et al. (2013) and Reif and Bluestein (2017) revealed the climatological characteristics of CI in the United States using a long period of archived radar mosaic maps. Using historical radar mosaic maps to derive a CI dataset may inspire the study of CI climatology over other regions.

Eastern China is a well-known "natural convection laboratory" to study convective processes because of the frequently occurring thunderstorms in the warm season. Over that area, a densely deployed weather surveillance radar network has been established in the past 20 years (Fig. 1). This network offers a good opportunity to study CI climatology in this region. However, the CI climatology for long-term and large spatial coverage over eastern China has not been done, partly because of dataquality issues. Fortunately, in recent years, the China Meteorological Administration (CMA) has made great efforts to produce national radar mosaic maps with a series of improved quality-control procedures. Thus the recent radar products have a great potential for studying CI climatology in eastern China. Before reaching that point, the feasibility of both the data and the CI-detection framework should be specifically examined. Such an examination would also be of a valuable reference for other regions.

The purpose of this study is to examine the feasibility of applying quality-controlled radar mosaic maps to formulate CI statistics in China using a simple CI-detection
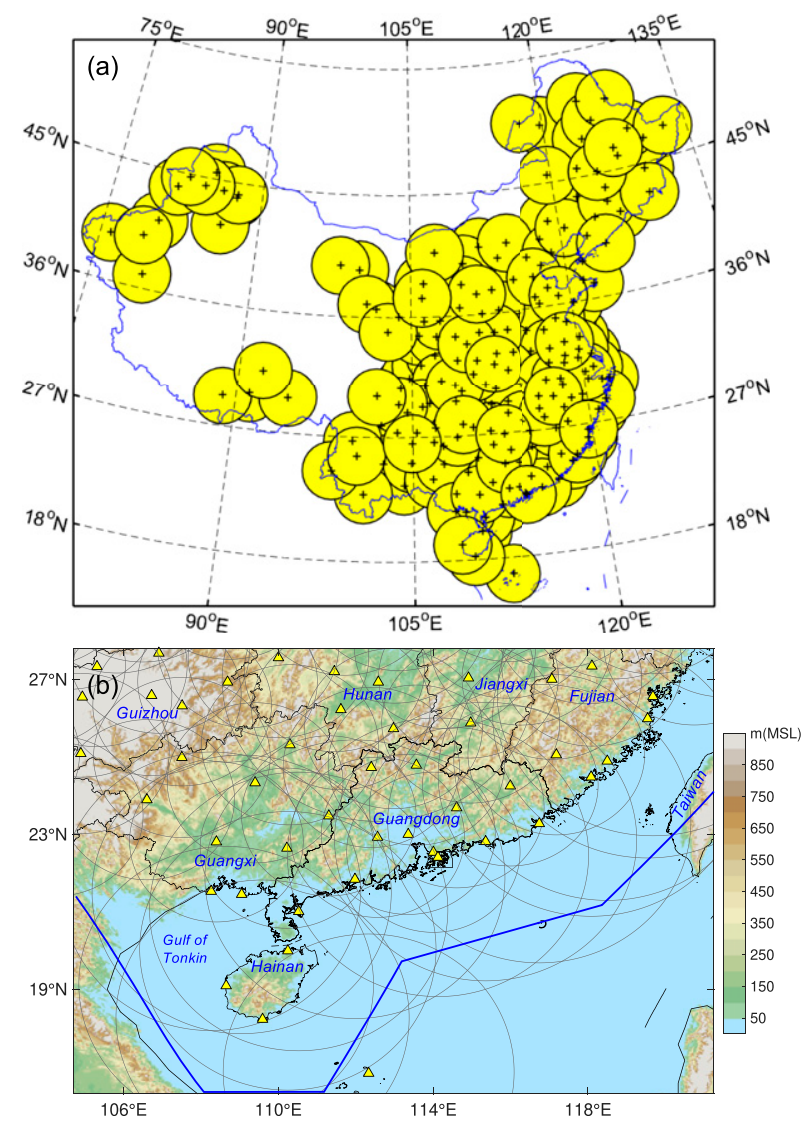

FIG. 1. (a) CINRAD coverage. The 230-km ranges from the 198 radar sites (crosses) are indicated by circles. (b) Terrain heights (shaded; meters above mean sea level) and locations of CINRADs (triangles) in South China. The blue line outlines the area described in Fig. 4a.

framework. The rest of this paper is organized as follows. In section 2, the radar data in China, procedures of retrieving the reflectivity from radar mosaic maps, and assessment of systematic bias of the retrieved reflectivity are introduced. In section 3, the framework for CI identification is described. In section 4 , the identified CI events are verified by comparing them with the rainfall in terms of the spatial consistency and the diurnal cycle. In the final section, a summary and discussions are presented.

\section{Radar data and image processing of radar mosaic maps}

\section{a. Radar data and radar mosaic maps in China}

The CMA started to build the China Next Generation Weather Radar (CINRAD) network in 1998 (Yu et al. 2006). By the end of 2012, 178 CINRADs had been deployed, 144 of which have been placed into operation (Bai 2013). Mainland China now has at least 
(a) Original radar mosaic map

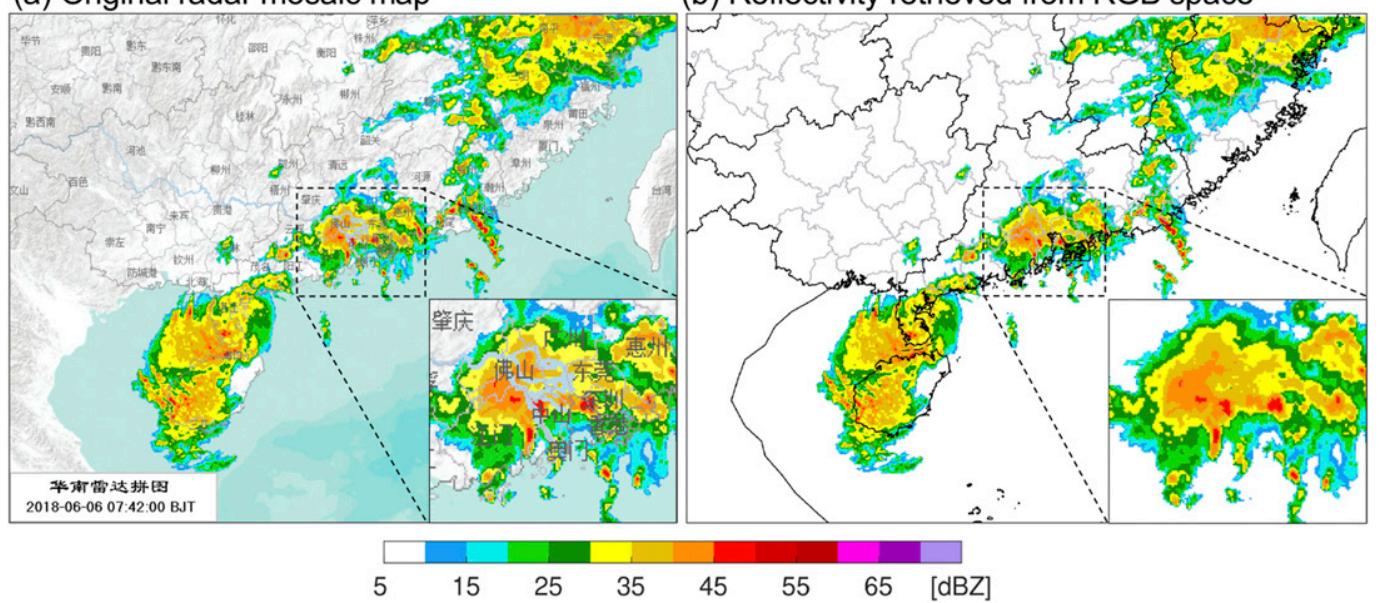

FIG. 2. (a) Example of an original radar mosaic map (reflectivity shaded; dBZ) in South China. (b) Reflectivity extracted from the color space of (a) as described in the text.

198 CINRADs (and counting) in operation (Fig. 1a). In eastern China, the majority of CINRADs are S-band radars and conform to the standards of Weather Surveillance Radar-1988 Doppler (WSR-88D) in the United States in terms of both hardware and software (Yu et al. 2006). CINRADs typically operate in the volume coverage pattern 21 (VCP21) mode, which includes nine-elevation volume scans (i.e., $0.5^{\circ}, 1.5^{\circ}$, $2.4^{\circ}, 3.4^{\circ}, 4.3^{\circ}, 6^{\circ}, 9.9^{\circ}, 14.6^{\circ}$, and $\left.19.5^{\circ}\right)$ with a volumetric update time of approximately $6 \mathrm{~min}$. The reflectivity data are collected in $1.0-\mathrm{km}$ range bins approximately every $1^{\circ}$ in azimuth. The maximum radar range for the S-band CINRADs is $460 \mathrm{~km}$.

The historical radar mosaic maps of reflectivity were used for the CI research, partly because of the unavailability of long-term grid radar mosaic data in this study. They were produced by the National Meteorological Center of CMA (available online at http://eng.nmc.cn/ publish/radar/chinaall.html). These publicly accessible mosaic maps have been involved a series of complicated procedures to composite multielevation scans of multiple individual radars, such as data quality control and removing systematic deviations of different radars. A radar mosaic map presents the basic reflectivity (equivalent radar reflectivity factor). The reflectivity value to be used for each range and azimuth bin is an optimal selection from the lowest three elevation angles (i.e., $0.5^{\circ}, 1.5^{\circ}$, and $2.4^{\circ}$ ), which is also called a "terrain-based hybrid scan" (Fulton et al. 1998). To avoid missing data due to radar beam blockage, the reflectivity values of neighboring radars will be used. Consequently, the reflectivity shown on the mosaic map is generally at low altitudes. These mosaic maps are produced with eight geographic sectors: contiguous China,
Northeast China, North China, South China, Central China, Northwest China, Southwest China, and East China. They are generated in real time every $20 \mathrm{~min}$ through 22 September 2008 and then every $10 \mathrm{~min}$ thereafter (Meng et al. 2013). The time interval further decreases to $6 \mathrm{~min}$ beginning on 15 June 2016. Figure 2a presents an example of the radar mosaic map in South China. The reflectivity is displayed on 12 scales at a $5-\mathrm{dB} Z$ increment from $10 \mathrm{~dB} Z$. Previous studies have suggested a reflectivity threshold of $40 \mathrm{~dB} Z$ (or $35 \mathrm{dBZ}$ ) to determine convection and discriminate between convective and stratiform rain (e.g., Rickenbach and Rutledge 1998; Parker and Knievel 2005; Wilson and Roberts 2006). Taking advantage of data quality control, the CI statistics in this study relied on the radar mosaic maps that were generated in real time with the approaches used at that time.

To be usable for climatological research, the radar mosaic data should be of good quality. In recent years, the CMA has applied many advanced methods to improve the quality of radar mosaics. A series of quality-control procedures have been performed to clear the ground clutter of single-site radar base data, intermittent point clutter and abnormal echoes (singularity or noise), to correct the attenuation of radar rainfall areas, and so on. Observations from geostationary satellites are also used to remove nonmeteorological echoes in the clear sky. With CMA's great efforts, the publicly available radar mosaic maps have achieved fairly good quality in recent years. The range-dependent echoes around radar sites and some possible abnormal echoes seem to have been effectively cleaned (e.g., Figs. 3a-d). Although the processes used to make mosaic maps have been evolving, the primary behaviors of precipitation echoes can 

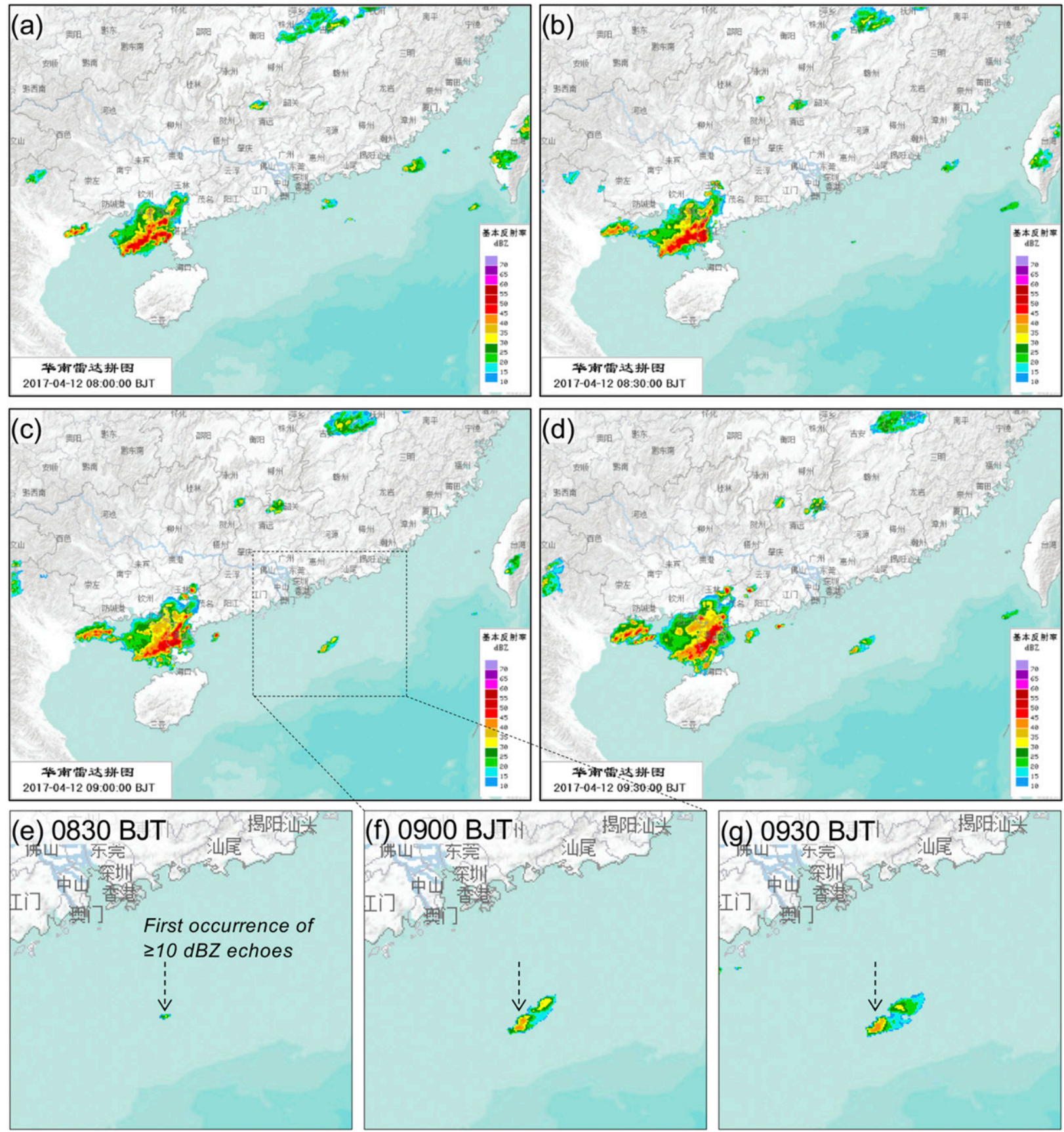

FIG. 3. Radar mosaic maps valid at (a) 0800, (b) 0830, (c) 0900 and (d) 0930 BJT 12 Apr 2017. (e)-(g) Snapshots enlarged from (b)-(d), respectively. The dashed arrow denotes the location of the first-occurrence echoes $(\geq 10 \mathrm{~dB} Z)$ for reference.

be extracted as long as nonmeteorological echoes are reasonably well filtered.

\section{b. Reprocessing of radar mosaic maps}

To evaluate the radar mosaics and test the CI-detection framework, we chose a rainfall-rich month (June 2017) over South China as an example, partly due to the wellestablished dense observation network in that region.
The monthly rainfall accumulation is usually largest in June over South China (e.g., Fig. 4a). Frequent convection occurrences have been demonstrated to be responsible for the large rainfall accumulation (Luo et al. 2013, 2017; Zhang et al. 2017). The radar mosaic maps in South China were available every $6 \mathrm{~min}$ and conformably constructed by $800 \times 600$ grid points. The average grid spacing (horizontal resolution) was approximately 

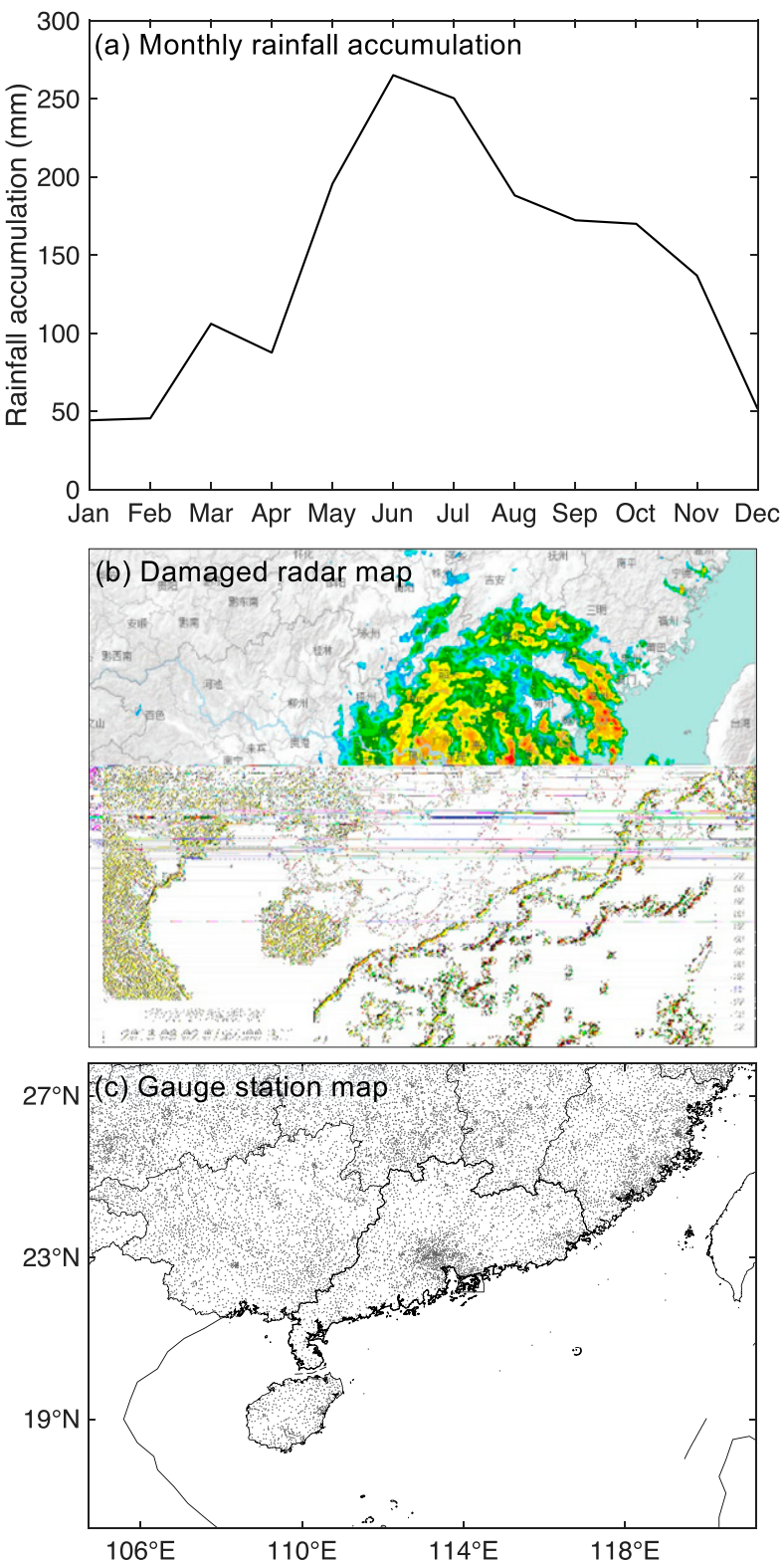

FIG. 4. (a) Monthly rainfall accumulation averaged over South China in 2017. Rainfall accumulation was calculated within the area north of the blue line as shown in Fig. 1b. (b) An example to show an obviously abnormal or damaged mosaic map. (c) Locations (dots) of the automated weather stations deployed in South China.

$2.15 \mathrm{~km}$. We first manually removed the clearly abnormal and damaged images (e.g., Fig. 4b). Such poor images were clearly standing out, and barely any subjective judgment was involved. After this eye-inspection quality-control procedure, there were 7108 usable images of a total of 7200. Thus, the dataset is $98.7 \%$ usable.

The reflectivity was extracted from the red-greenblue (RGB) color space on the radar mosaic maps. By reading the $\mathrm{RGB}$ color at each image pixel, the reflectivity values were retrieved by assigning the corresponding index values as shown on the color bar. Approximately $5.4 \%$ of the pixels on a mosaic map are covered by geographical boundaries (e.g., coastlines, lakes, and rivers) and Chinese characters. The resultant missing reflectivity values were restored using the Cressman interpolation method (Cressman 1959). The weighting function of the interpolation applied an influence radius of $12.9 \mathrm{~km}$. Figure 2 presents an example of the comparison between an original radar mosaic map and the interpolated one. It seems that the reproduced reflectivity values at data-missing pixels are fairly reasonable, which provides confidence in the climatological use of these images. The grid reflectivity data reproduced from the radar mosaic maps were finally prepared for use after geolocating each pixel using geometric techniques (Fig. 2b). Hereinafter, the reproduced grid reflectivity is referred to as mosaic-retrieved reflectivity for convenience.

\section{c. Assessment of the systematic bias of the mosaic-retrieved reflectivity}

To build a radar-echo climatology, the systematic bias of the mosaic-retrieved reflectivity must be evaluated. Because of the ground return of radar beams, one may find range-dependent features around radar sites. Such radar site-dependent behavior will be magnified in a long-period composite, and meteorological features are likely overridden. To examine whether a systematic bias exists around any radar sites in the long-term statistics, we compared the accumulative rainfall estimated from radar mosaic maps with that from rain gauges or satellites. We used the quality-controlled hourly gauge data from CMA and the satellite rainfall of CMORPH (Joyce et al. 2004) to obtain the observed rainfall patterns. In South China, there are $\sim 10000$ rain gauges at a spatial resolution of $\sim 10 \mathrm{~km}$ (Fig. 4c) (Huang and Luo 2017). The CMORPH data have a spatial resolution of $8 \mathrm{~km}$ and a time interval of $30 \mathrm{~min}$. The radar-estimated rainfall is obtained by applying a single relationship between reflectivity $(Z)$ and rainfall rate $(R)$ of $Z=300 R^{1.4}$ (Fulton et al. 1998) to the entire study domain.

Over the coastal areas, the radar-estimated rainfall accumulation on land shows a spatial pattern generally analogous to that of gauge estimates, especially in Guangdong Province (Figs. 5a,b). In the offshore areas where gauge data were unavailable, the radar-estimated rainfall pattern was also consistent with that derived from satellites (Figs. 5a,c). However, the radar-estimated rainfall accumulation over the western highland (Guangxi and Guizhou) was less than that of the gauge and satellite estimates (Figs. 5a-c). We noticed that the lower 
(a) Radar-estimated rainfall accumulation

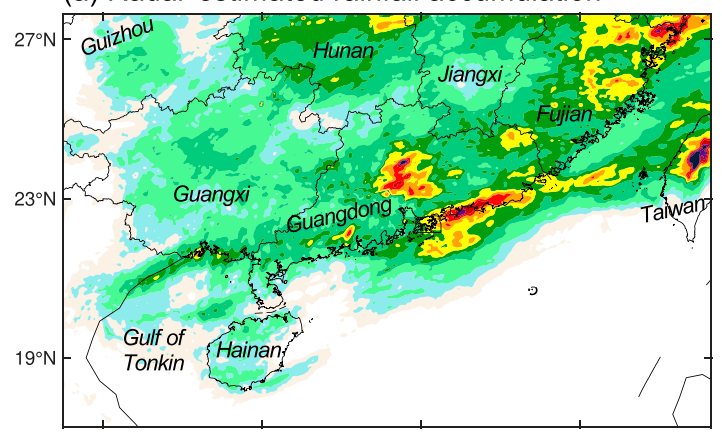

(c) Satellite-estimated rainfall accumulation

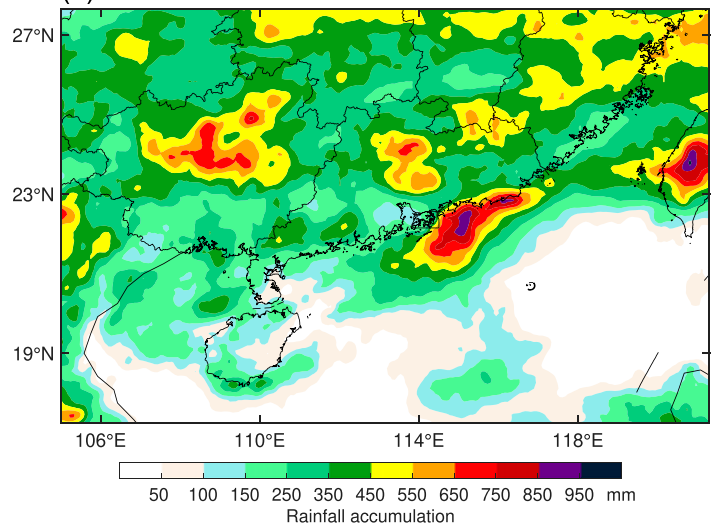

(b) Gauge-estimated rainfall accumulation

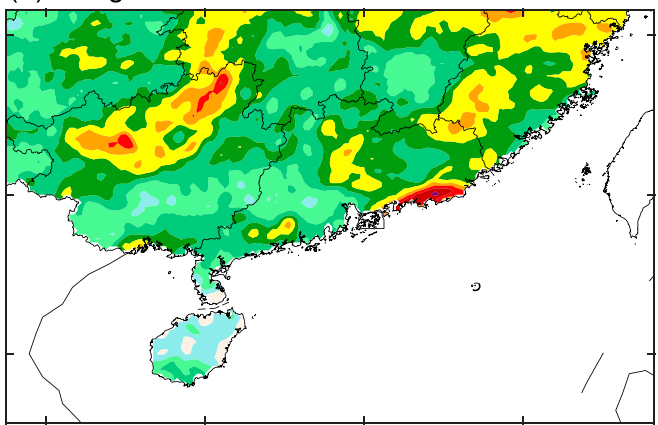

(d) Frequency of $\geq 40 \mathrm{dBZ}$ pixels

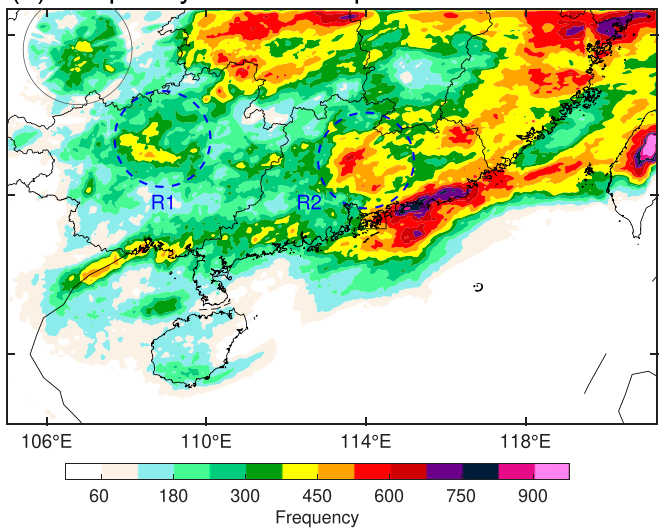

FIG. 5. Rainfall accumulation in June 2017 estimated from (a) radar mosaic maps, (b) rain gauges, and (c) satellites (CMORPH). The color scale for (a)-(c) is presented at the bottom-left corner of the figure. (d) Frequency of the convective echoes $(\geq 40 \mathrm{dBZ})$ derived from the radar mosaic maps in June 2017. The dashed circles R1 and $\mathrm{R} 2$ denote the regions described in the text. The solid circle indicates the range-dependent feature that is described in the text.

tilts of some CINRADs deployed in this region were subject to the topographic blockage (not shown), which likely resulted in the rainfall underestimation. In the case of blockage, the reflectivity to be used at the blocking points is usually obtained from neighboring radars. Thus, such reflectivity values tend to represent the sampling of hydrometeors at relatively high levels and thereby may be less representative of the precipitation systems with lower vertical extent.

In the CI statistics, we pursuit a reasonable identification of convective echoes rather than a perfect estimation of radar-derived rainfall comparing with the gauge- or satellite-based rainfall estimates. To examine whether the radar beam blockage in Guangxi has affected the identification of $\mathrm{CI}$, we further calculated the frequency of convective echoes ( $\geq 40 \mathrm{dBZ}$ ) in June 2017 (Fig. 5d). As expected, a local maximum in convective echo occurrence is located in Guangxi, though it is not standing out as that at coastal regions. Specifically, the averaged occurrence within the circle R1 as shown in Fig. $5 \mathrm{~d}$ is 275 per grid, which is about $75 \%$ of that within the circle R2. The detection of convective echo occurrence was not so strongly affected by the beam blockage over Guangxi despite of the rainfall underestimation. On the other hand, the constantly occurring spurious echoes with convection strength should not be allowed. In practice, no abnormally high frequency of convective echoes is spotted in Fig. 5d. Nevertheless, we noticed a circle of rangedependent feature around a radar site in Guizhou (refer to the solid circle in Fig. 5d). The number of convective echoes sharply decreases outside this circle, indicating a possible negative bias in the CI statistics in that area. Considering the possible underestimation of CI occurrence when the beam blockage is occurring, some cautions should be taken when interpreting the results in Guizhou and the northwest Guangxi.

The ratio of the long-period mosaic-based rainfall accumulation to the gauge-based one is also helpful to reveal the likely systematic bias (e.g., constant overestimation or underestimation at some locations, uneven radar coverage) that may affect the final statistics (Fabry et al. 2017). If there are persistent spurious echoes in any region, we expect an extremely large ratio due to their long-period accumulated effects. 
(a) Ratio of radar-to-gauge accumulation

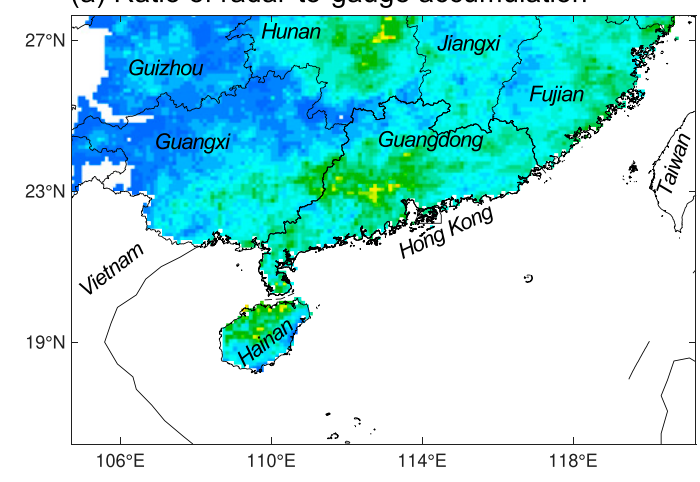

(b) Ratio of radar-to-CMORPH accumulation

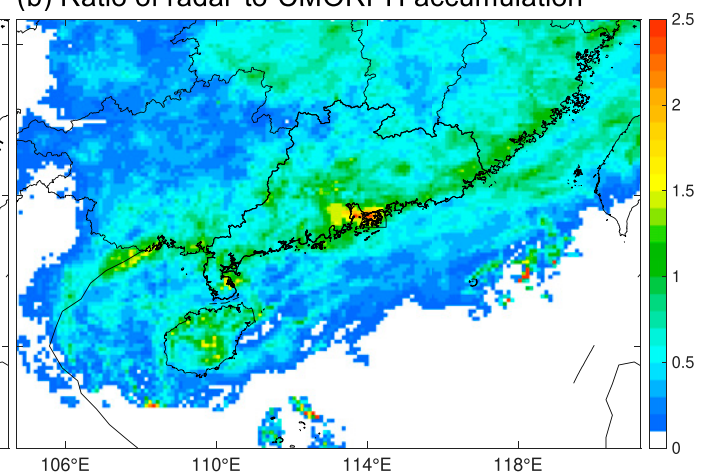

FIG. 6. Ratio of radar-estimated rainfall accumulation (Fig. 5a) to (a) gauge-estimated (Fig. 5b) and (b) satelliteestimated (Fig. 5c) rainfall accumulation in June of 2017.

By referring to the radar locations and topographic features (Fig. 1b), there was no abnormally large value spotted around the radar sites or mountain edges (Fig. 6a). When the rainfall is constantly underestimated at a given location, a small ratio was expected. Over Guizhou and the northwest Guangxi, the ratio is relatively small (Fig. 6a). The rainfall underestimation caused by the radar beam blockage is probably responsible for the small ratio in that area. Nevertheless, the spatial patterns of CI occurrence may be recognized though the number of convective echoes was somewhat underestimated (Fig. 5d). Over that region, some radar echoes were given by adjacent radars due to the beam blockage issue. Nevertheless, to some extent, the highaltitude convective echoes of deep moist convection tended to be detected. In the near offshore where gauges were unavailable, satellite rainfall estimates were used to calculate the ratio (Fig. 6b). There is generally no abnormally large ratio offshore except for several scattered points, which is likely because of the small rainfall accumulation (Figs. $6 \mathrm{~b}$ and $5 \mathrm{c}$ ). The ratio is relatively large over the Hong Kong region where the CMORPH rainfall is actually underestimated due to a mishandling of gauge records for calibration (Chen et al. 2018). Overall, the above analyses suggest that the quality issues of radar mosaic maps have been fairly well resolved, and the mosaic-retrieved reflectivity is feasible to calculate the CI statistics.

\section{Framework for CI detection}

\section{a. Description of the CI-detection framework}

In this section, the framework that was applied to identify CI events is described. The framework contains three main parts: (i) preparing the reflectivity data as introduced in section 2, (ii) detecting convective cores and applying $\mathrm{CI}$ algorithms to identify $\mathrm{CI}$ occurrences, and (iii) checking the quality of the identified CI events. A reflectivity threshold of $40 \mathrm{dBZ}$ was used to locate the convective region. The detailed procedures are presented as follows (Fig. 7):

1) Remove the clearly abnormal and damaged radar mosaic maps.

2) Extract the reflectivity from the RGB color space on radar mosaic maps.

3) Restore the missing reflectivity covered by geographical boundaries and characters.

4) Dichotomize (or "binarize") the reflectivity ( $\geq 40 \mathrm{dBZ}$ and $<40 \mathrm{~dB} Z$ ) to distinguish the convective region (Figs. 8a,d).

5) Locate all of the spatially connected convective segments, namely, convective cores (Fig. 8e). Only those that consist of at least two pixels are considered to eliminate some possibly invalid convection.

6) Identify the first-occurrence convective cores that are defined as no convective echo occurring within the previous $30 \mathrm{~min}$ within a radius of $30 \mathrm{~km}$.

7) Apply CI algorithms (section 3b) to the first-occurrence convective cores and record the time and locations of the identified CI events.

8) Check suspicious CI outbreaks in the CI statistics and remove the clearly abnormal CI samples.

\section{b. Algorithms used to identify CI events}

The algorithm used to determine a CI event was designed by slightly modifying that put forth by Fabry et al. (2013, hereinafter referred to as the FCB13 algorithm). In Fabry et al. (2013), the velocity of a candidate convective cell was first computed and the following conditions were applied to the previous location of the candidate cell: 1) no pixel above $25 \mathrm{dBZ}$ was observed $30 \mathrm{~min}$ prior to the convection event within $30 \mathrm{~km}$ of the 


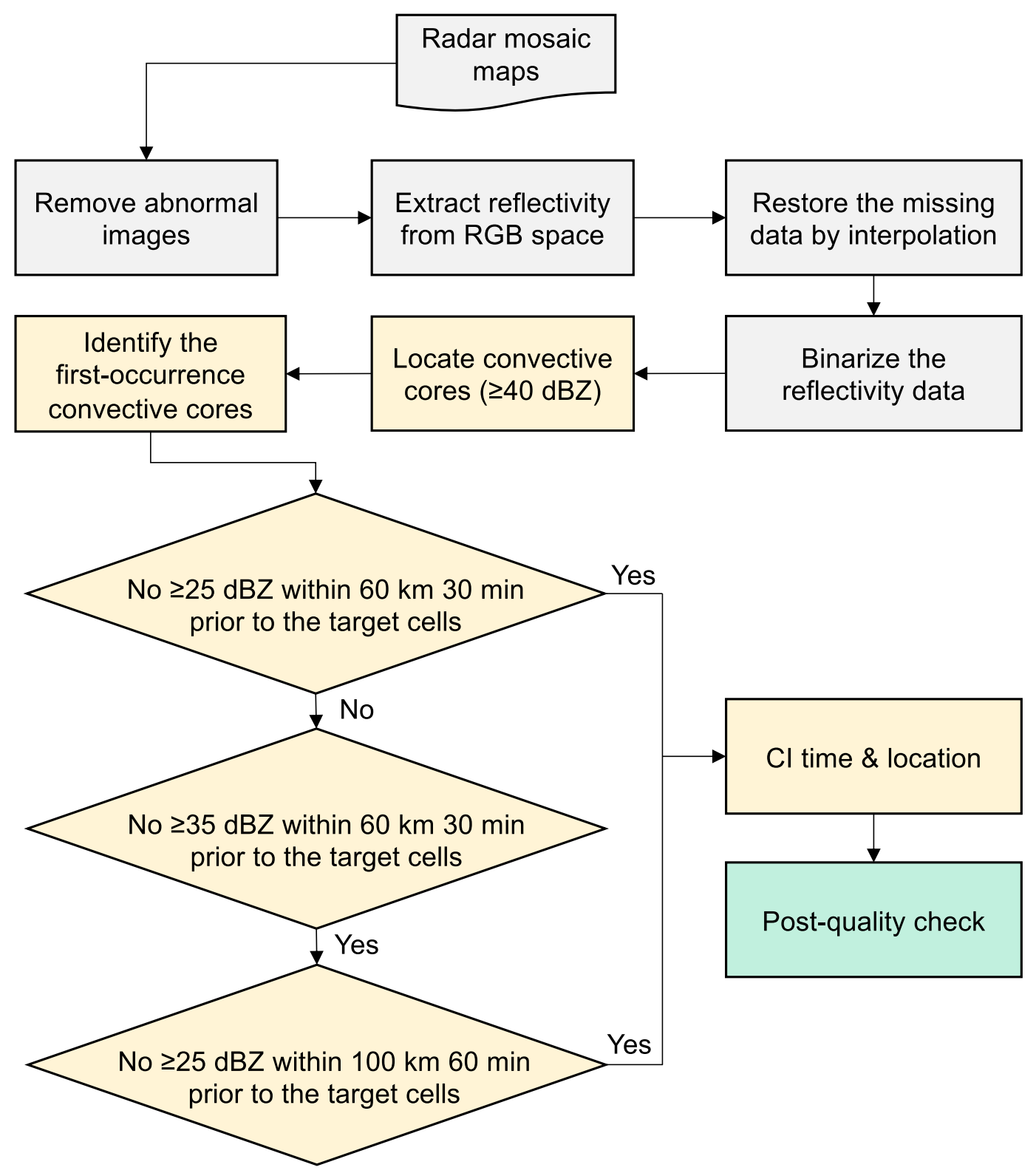

FIG. 7. Flowchart of the CI-detection framework.

expected position of the cell (e.g., the position denoted by the black dot in Fig. 9), or 2) no pixel reaching $35 \mathrm{dBZ}$ was observed $30 \mathrm{~min}$ prior to the convection event within $30 \mathrm{~km}$ of the expected position of the cell, and no pixel exceeding $25 \mathrm{dBZ}$ was observed $60 \mathrm{~min}$ prior to the convection event within $50 \mathrm{~km}$ of the expected position of the cell. Given that there may be large uncertainty in estimating the motions of scattered small-size storms, we chose a stricter criterion to avoid the estimation of the storm motion in this study. Assuming a newborn convective cell has a translation speed of $15 \mathrm{~m} \mathrm{~s}^{-1}$ [for squall lines in Meng et al. (2013)], the displacement of the cell within 30 or $60 \mathrm{~min}$ is 27 or $54 \mathrm{~km}$, respectively.
Thus, we slightly modified the FCB13 algorithm by applying larger radii (hereinafter referred to as the FCB13_modified algorithm) as follows:

1) No pixel above $25 \mathrm{dBZ}$ was observed $30 \mathrm{~min}$ prior to the candidate convective cell within $60 \mathrm{~km}$ of the current position of the cell (e.g., the position denoted by the red dot in Fig. 9), or

2) no pixel reaching $35 \mathrm{~dB} Z$ was observed $30 \mathrm{~min}$ prior to the candidate convective cell within $60 \mathrm{~km}$ of the current position of the cell, and no pixel exceeding $25 \mathrm{~dB} Z$ was observed $60 \mathrm{~min}$ prior to the candidate convective cell within $100 \mathrm{~km}$ of the current position of the cell. 

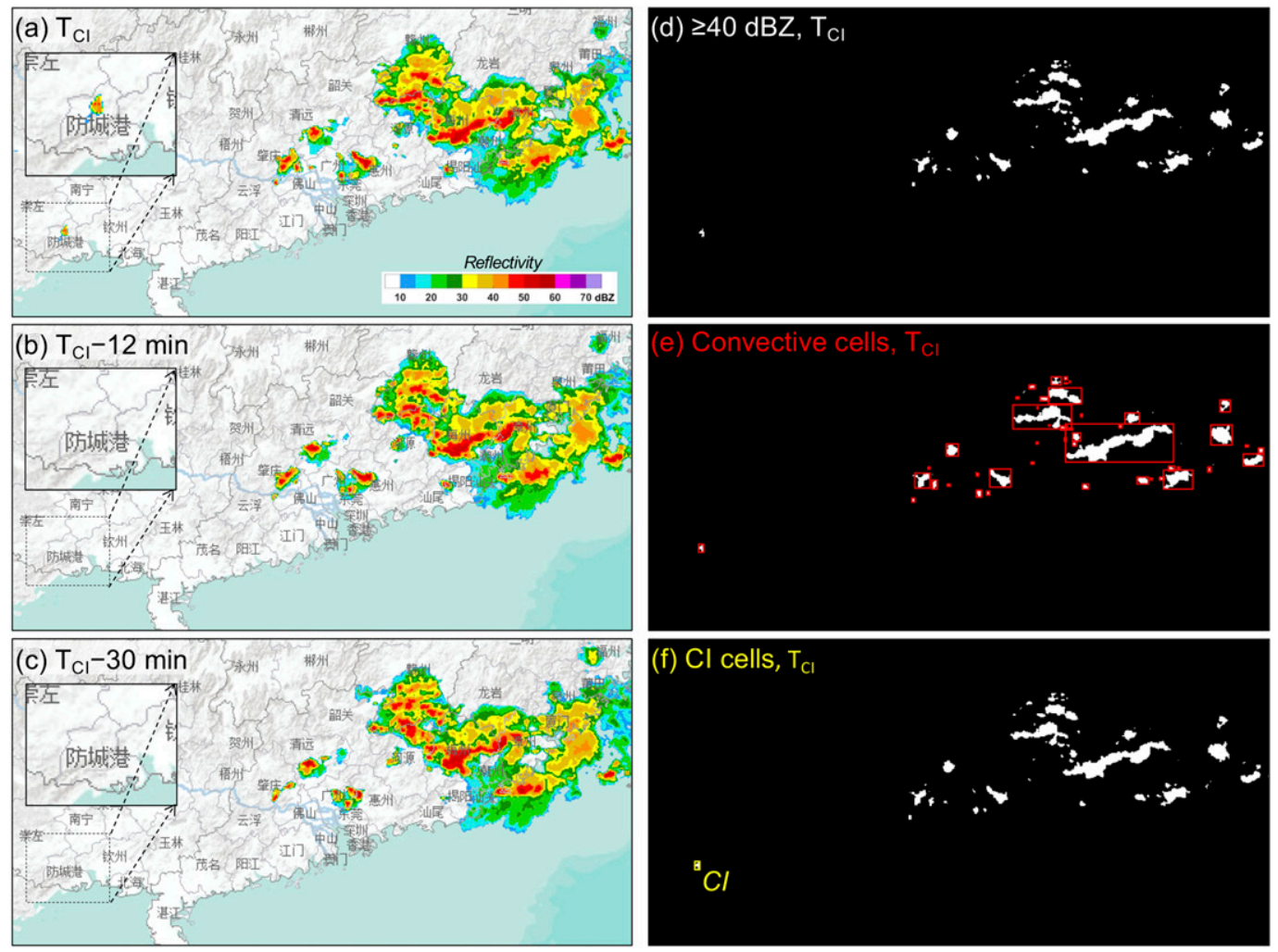

FIG. 8. Example of a CI event identified by the framework. (a)-(c) Snapshots of original radar mosaic maps in South China (reflectivity shaded; dBZ). (d) Reflectivity ( $\geq 40 \mathrm{dBZ}$; white) extracted from the color space of (a). (e) The connected segments of the reflectivity in (d) are detected as individual convective cores (labeled with red rectangles). (f) The CI event identified by the CI-detection framework is labeled with the yellow rectangle.

As shown in Fig. 9, the FCB13_modified algorithm checks the image pixels in a larger spatial domain than the FCB13 algorithm. However, it is easier to operate because storm motions are not estimated. Thus, the FCB13_modified algorithm could be regarded as a less complicated version of the FCB13 algorithm. Since the FCB13_modified algorithm employs more rigorous criteria, it is expected to identify fewer CI samples than the FCB13 algorithm. Considering the discrepancy of CI counts between the two algorithms, we will examine whether they can produce consistent spatial patterns of CI occurrence. Additionally, according to the definition of the FCB13_modified algorithm, it tends to identify isolated convective storms. Most secondary CI events (i.e., CI influenced by near existing convective storms) will be ignored. It may also identify part of secondary CI samples, such as the convection triggered by outflow boundaries from existing storms that are more than $60 \mathrm{~km}$ away. An example of CI event identified by applying the FCB13_modified algorithm is presented in Fig. 8. There are 60 convective cores detected in Fig. 8e (refer to the red boxes), but only one of these cores is identified as a CI event at that time (refer to the insets in Figs. 8a-c and the yellow box in Fig. 8f). When a tropical cyclone is involved, the framework tends to identify the isolated convection initiated far from the well-organized rainbands. The number of such CI events would be few in a long-term CI dataset.

\section{c. Quality check of the identified CI events}

After registering the identified CI events, a machinebased algorithm was run to flag the radar mosaic maps that have suspiciously abnormally large CI samples. By manually checking the temporally contiguous mosaic maps, the CI samples identified from the clearly abnormal mosaic maps were removed. For instance, the FCB13_modified algorithm identified a large number of CI occurrences on a radar mosaic map, as shown in Fig. 10a. These suspicious CI occurrences are grouped within a localized area, forming a CI outbreak event (refer to the red ellipse in Fig. 10a). By manually checking the radar mosaics at adjacent scans, we found that there were no echoes within the previous $30 \mathrm{~min}$ of CI. The well-developed convective systems just appeared from nothing within 6 min (Figs. 10b,c). 


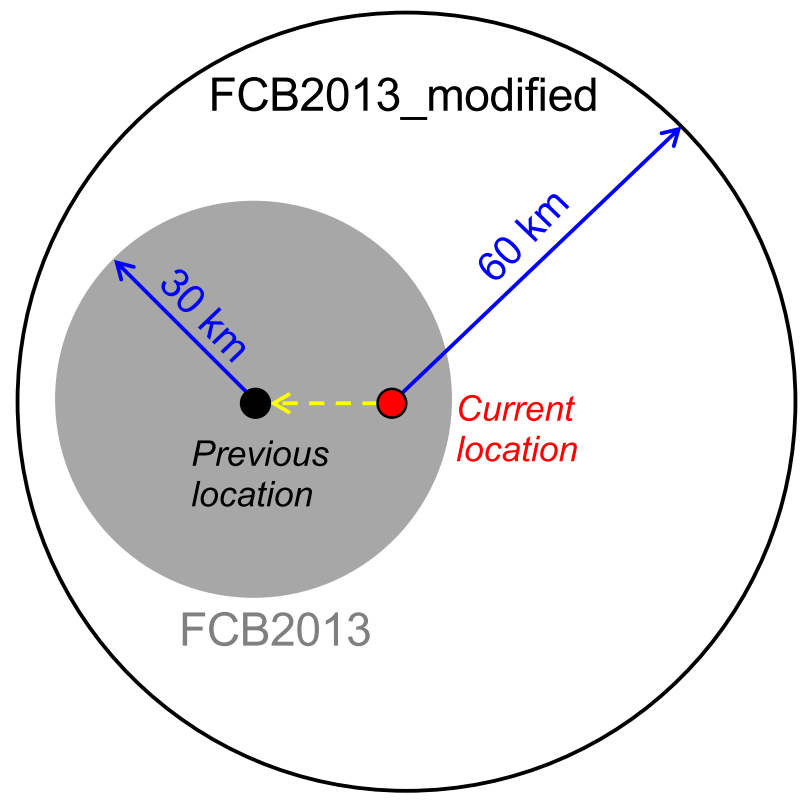

FIG. 9. Schematic diagram for presenting the search range of the FCB13_modified (black-outlined circle) and FCB13 (gray shaded) $\mathrm{CI}$ algorithms. The red dot denotes the current location of a convective cell, and the black dot represents its previous location as described in the text.

This issue may be a result of radar hardware failure or the delay in real-time data exchange during the mosaic-producing process. Such fake CI events should be removed from the CI statistics. In practice, this was a rare case.

Another algorithm was run to further flag the identified CI events in which the convective echoes appeared only once. For instance, the convective cells within the black ellipse in Fig. 10e occurred just once on the three successive radar mosaic maps and never showed up in other scans (e.g., Figs. 10d-f). These strong echoes oriented in parallel to radar beams were recognized as interference echoes that were not effectively cleared when making mosaic maps. Satellite products (e.g., brightness temperature) could be applied to screen such fake CI events from the CI statistics. In practice, this was also a rare case. The CI database was finally determined after these basic quality check procedures.

\section{Results and validation of the CI identification}

\section{a. Spatial distributions of CI occurrences and their sensitivity to CI algorithms}

Figure 11a presents the spatial distribution of the CI events identified using the FCB13_modified algorithm. There was a total of 366933 convective cores detected on the 7108 radar mosaic maps in June of 2017. Only 1286 of these convective cores were cataloged as CI events. Convection initiation primarily occurs over the coasts of South China. When compared with the FCB13 algorithm, The FCB13_modified algorithm basically gave an identical CI pattern (Figs. 11a,b), suggesting that the FCB13_modified algorithm works fairly well although it is a modified version of the FCB13 algorithm.

To identify a CI-prone region, we defined a hot spot of $\mathrm{CI}$ as a localized region where the number of $\mathrm{CI}$ occurrences is at least 6 times the background value (calculated by the domain average of CI occurrence). Following this definition, three distinct hot spots of CI were located: the Pearl River delta, coastal zones of Guangxi and Guangdong, and Hainan Island, which are labeled with A, B, and C, respectively. In addition to these CI hot spots, there were also a substantial number of CI occurrences over the mountain slopes in Guangxi Province, although the daily frequency of CI was lower than that around the coastal areas (Fig. 11a).

Most of the identified CI events occurred over the low-elevation areas. The highest CI frequency on land was observed in the Pearl River delta, as marked by A in Fig. 11a. In particular, the CI occurrences were concentrated near the windward slope of the mountain ranges to the east of the Pearl River delta, which coincides with the local maxima of climatological radar echoes (X. Chen et al. 2014, 2015). In that area, convection is particularly active in June due to the combined influence of monsoon flow and orographic lifting (X. Chen et al. 2016, 2017; Luo et al. 2017). The CIprone region $\mathrm{B}$ also agrees with previous findings that this area was characterized by a relatively high frequency of storms (Luo et al. 2017; Jiang et al. 2017; Fu et al. 2017). Notably, the CI occurrences were evident both on coastal land and offshore. The CI occurrences to the north of the Gulf of Tonkin may result from the enhanced convergence by land breezes and the accelerated monsoon southwesterlies at night (X. Chen et al. 2016).

Figure 11a also shows that Hainan Island is a CI-prone area (region C). There were substantial CI occurrences located both to the south and north of the mountains over the island while the rainfall accumulation was overall small (Fig. 5b). The majority of CI events on the northern island were likely corresponding to the localized afternoon convection. Previous studies have demonstrated that the afternoon convection in the northern part of the island is closely associated with the activity of sea-breeze fronts (Zhu et al. 2017). The collision of sea breezes from the west and east sides of the island is 


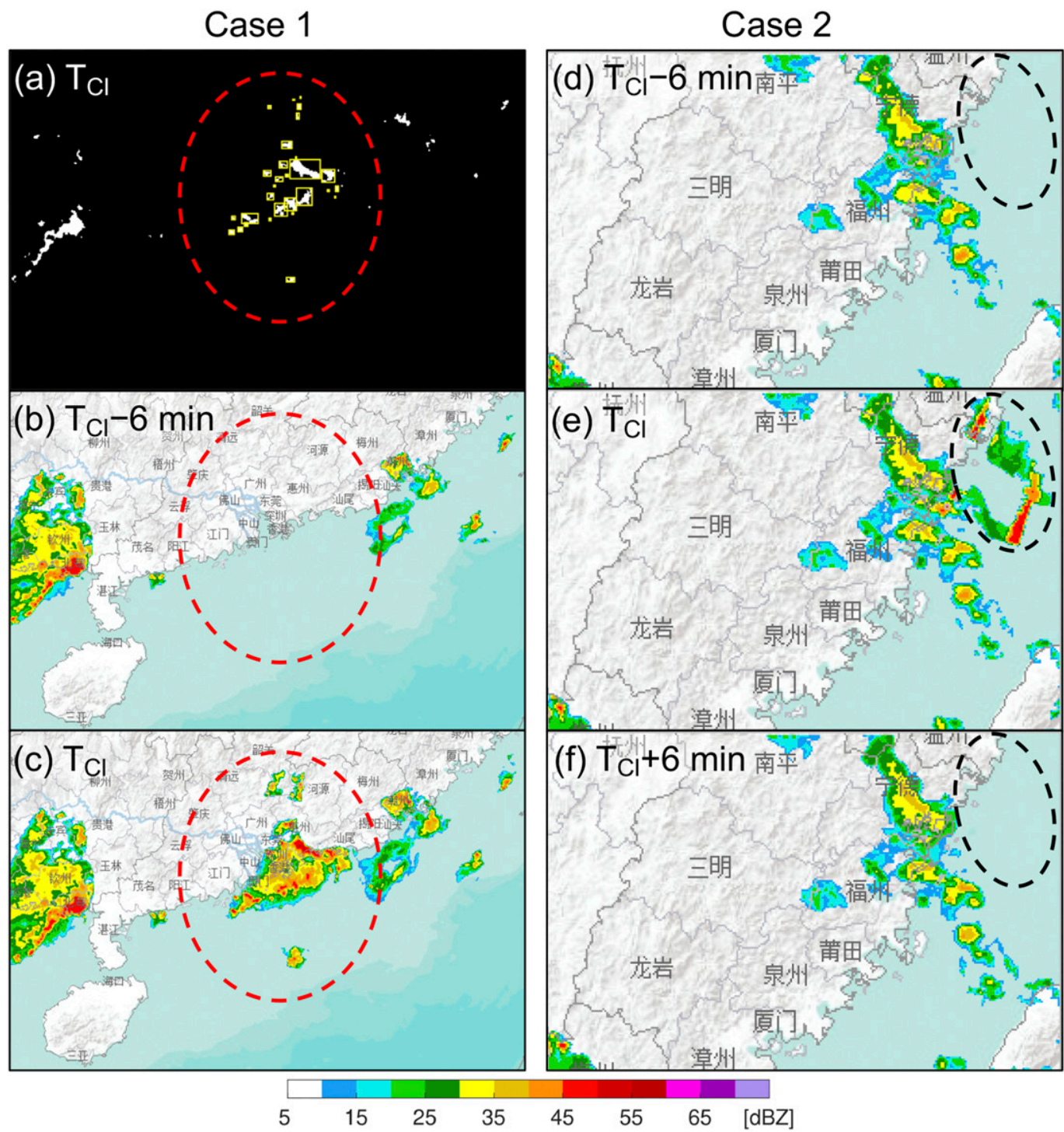

FIG. 10. Examples of the identified CI events that are rejected by the postidentification quality control: (a) The identified CI cells at the CI time for case 1 are denoted by yellow rectangles. (b),(c) Snapshots of the radar mosaic maps for case 1 at 6 min prior to and at the CI time, respectively. Also shown are snapshots of the original radar mosaic maps for case 2 at (d) -6 , (e) 0 , and (f) +6 min relative to the CI time. The ellipses are plotted for reference as described in the text.

responsible for producing the prevalent afternoon peak in rainfall. Similar to the CI occurrences on the windward coasts of Guangdong and Guangxi, the CI events that occurred at the southern coasts of Hainan Island probably resulted from the enhanced monsoonal flows and orographic lifting in the morning (X. Chen et al. 2017; G. Chen et al. 2018). Overall, the spatial patterns of the identified CI over South China are generally consistent with those of the rainfall climatology revealed by previous studies.

To examine whether the spatial pattern of CI occurrences is dependent on the specific identification criteria, we performed an alternative $\mathrm{CI}$ algorithm proposed by Reif and Bluestein (2017; hereinafter referred to as the RB17 algorithm). The RB17 algorithm defines a CI event as the first occurrence of a convective cell $(\geq 40 \mathrm{dBZ}$ ) around which no other convection occurred within a radius of $100 \mathrm{~km}$ in a 3-h period. This was designed for identifying the pristine convection in which CI was not influenced by other neighboring storms. More details can be found in Reif and Bluestein (2017). The RB17 algorithm certainly rejects a mass of valid initiation events because it contains much stricter conditions than the FCB13_modified algorithm. The number of CI events identified by the RB17 algorithm was 
(a) FCB13_modified

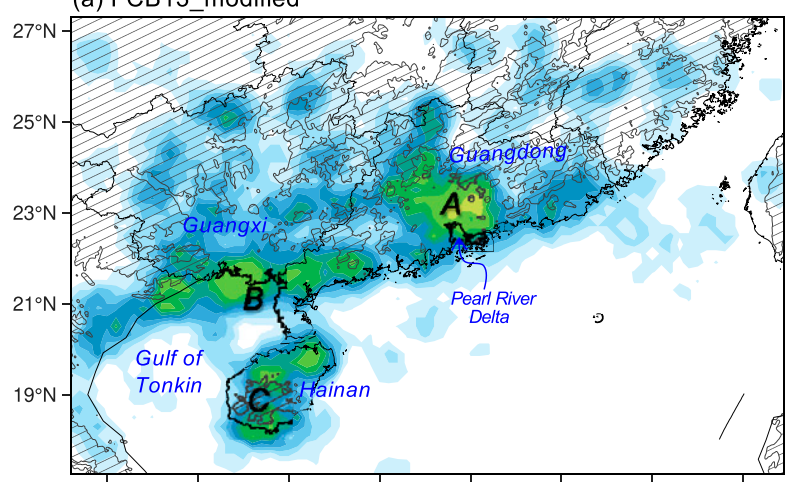

(b) FCB13

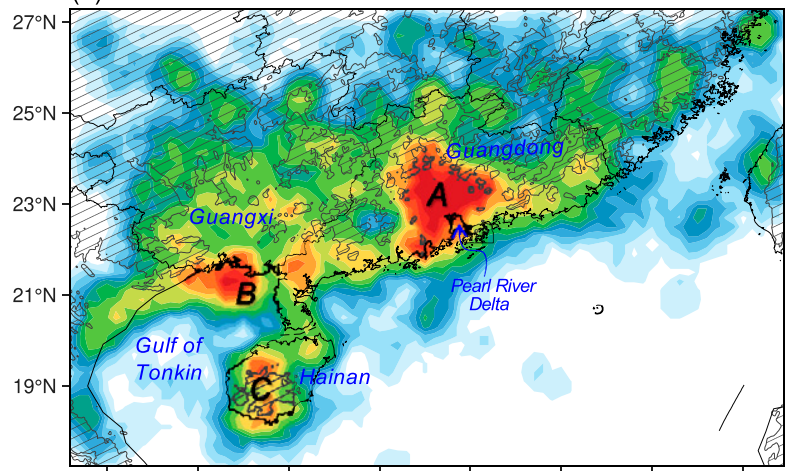

(c) RB17

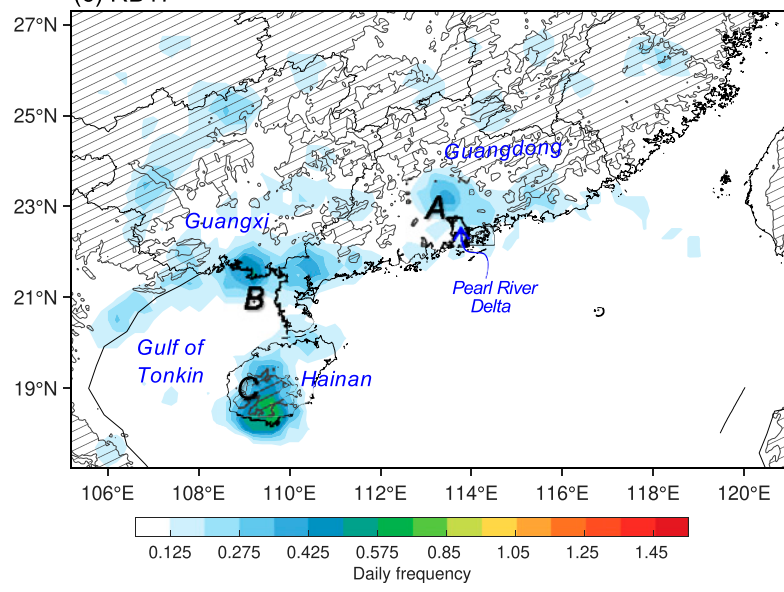

FIG. 11. Daily frequency of the identified CI events (color shaded) by the (a) FCB13_modified, (b) FCB13, and (c) RB17 algorithms in June of 2017 over South China. The hot spots of CI occurrences labeled with A, B, and C are described in the text. The hatched area within the contours indicates the terrain at an altitude of $250 \mathrm{~m}$.

454, which is smaller than that of the FCB13_modified algorithm (1286). Although the RB17 algorithm identified fewer CI samples, the spatial pattern of CI occurrences still shows three major CI-preferred regions (Fig. 11c), which are consistent with those obtained from the FCB13_modified algorithm (Fig. 11a). We noticed that the $\mathrm{CI}$ occurrences identified by the RB17 algorithm in the northern Hainan were less frequent than those in the southern part, which is in contrast with those by the FCB13_modified algorithm (Figs. 11a,c). Such a discrepancy was likely due to the prevailing southwesterly winds in June. The new convection initiated in the northern Hainan may be located close to the upstream preexisting storms, and thus it is rejected by the RB17 algorithm because that algorithm tends to identify the pristine CI. As the prevailing winds turn into southeasterlies after July, such a discrepancy between the two CI algorithms disappears (not shown). In general, the CI-prone regions can be revealed reasonably well though the number of identified CI occurrences varies with the CI algorithms. Although the FCB13_modified algorithm applied more rigorous conditions than the FCB13 algorithm, it is easier to operate but can also generate fairly reasonable CI statistics.

\section{b. Duration of precipitation echoes corresponding to the identified CI cells}

To verify the validity of the identified CI events, all the cataloged CI cells obtained by the FCB13_modified algorithm were manually checked by tracking the cells until their radar reflectivity fell under $10 \mathrm{~dB} Z$. A valid CI event was flagged when the precipitation echoes had a relatively long duration (greater than $20 \mathrm{~min}$ ) and a systematically (against randomly) moving behavior in the animation (e.g., Figs. $3 e-g$ ). If the precipitation echoes finally merged with other organized and larger-sized storms, the duration time was counted until the merger. In practice, these CI-related precipitation echoes often clearly grew both in intensity and size. Here we manually tracked the convective cells to ensure that the identified CI events are reliable. Other tracking techniques such as Thunderstorm Identification, Tracking, Analysis, and Nowcasting (TITAN; Dixon and Wiener 1993) are needed when the analysis on storm life in a large CI dataset is involved.

According to the manual check, nearly all the analyzed convective cells had an organized motion. Only two samples had a duration of less than $20 \mathrm{~min}$, and the other three clearly resulted from interference echoes (e.g., Figs. 10d-f). These five samples were removed from the CI database. The precipitation echoes for approximately $75 \%$ of the CI cells lasted for more than $1.5 \mathrm{~h}$ (Fig. 12a). The median value of the duration was approximately $2.5 \mathrm{~h}$. Some storms were even maintained for more than $10 \mathrm{~h}$. Therefore, the manual verification suggests that the CI statistics obtained from the framework are physically reliable and barely affected by dataquality issues. 

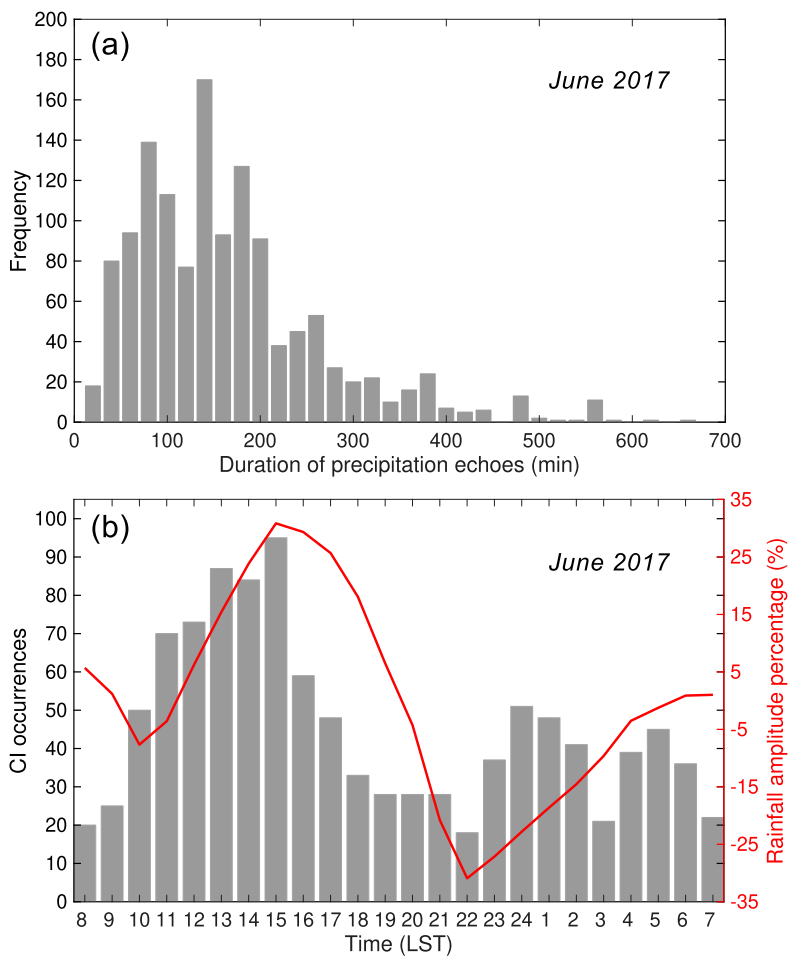

FIG. 12. (a) Histogram for the duration ( $\mathrm{min}$ ) of precipitation echoes $(\geq 10 \mathrm{dBZ})$ of the identified CI cells, and (b) diurnal cycle of $\mathrm{CI}$ occurrence (bars) and the domain-averaged rainfall amplitude (red curve) in June of 2017. The domain-averaged rainfall amplitude was first calculated on each grid point and then averaged within the area north of the blue line as shown in Fig. 1b.

\section{c. Comparing the CI occurrences with rainfall}

The analysis of rainfall characteristics such as diurnal variations often bridges the inherent connection between convective activity and thermal/dynamic forcings over inhomogeneous underlying surfaces (Ohsawa et al. 2001; G. Chen et al. 2009, 2012; X. Chen et al. 2016). To further examine whether there was visible noise or abnormal features in the CI statistics, we performed an analysis on the temporal variations in the identified CI events and rainfall. The rainfall statistics were calculated within generally the same spatial coverage as the radar network (refer to the blue line in Fig. 1b). Because of the unavailability of gauges at sea, the rainfall estimates were obtained from the CMORPH products. Figure $12 \mathrm{~b}$ shows the diurnal variations in the $\mathrm{CI}$ occurrences and monthly mean of hourly rainfall amplitudes (RA); RA is defined as

$$
\mathrm{RA}=\frac{R_{t}-\bar{R}}{\bar{R}},
$$

where $R_{t}$ is the rainfall amount at each hour and $\bar{R}$ is the mean hourly rainfall amount during a day.
Figure $12 \mathrm{~b}$ shows that a majority $(62 \%)$ of $\mathrm{CI}$ events occur during the daytime hours, whereas the rest (38\%) occurs at night or predawn. The CI becomes increasingly active from 1000 Beijing time (BJT; BJT $=\mathrm{UTC}+8 \mathrm{~h}$ ) and reaches a peak at $1500 \mathrm{BJT}$. Correspondingly, the hourly rainfall amplitude increases evidently near noon and peaks at 1500 BJT. The CI occurrences decrease dramatically at 1600-1900 BJT, while the hourly rainfall amplitude experiences a delayed decrease in the afternoon hours. Such a time lag is reasonable because the active rainfall is supposed to occur after the initiation of storms. Additionally, the hourly rainfall amount is the accumulation within the previous hour, which may also contribute to a delayed rainfall decrease. Figure $12 \mathrm{~b}$ also shows that both the CI occurrences and rainfall minimize at 2200 BJT, suggesting a suppressed convection stage. At midnight and predawn, the nocturnal CI occurrences emerge; the rainfall increases moderately and reaches its secondary peak in the early morning. The rainfall intensifies more rapidly after the $\mathrm{CI}$ in the daytime than at night. Such a difference seems reasonable because convective activity is usually intense in the daytime with thermal instability due to strong solar heating.

Figure 13a further shows that the CI peak hours exhibit three major spatial modes: evening-to-early-morning peak in the northwest highland, noon-to-late-afternoon peak in the coastal land, and late-night-to-morning peak on windward coasts and in offshore areas. These spatial modes are in good agreement with those of rainfall (Fig. 13b). These modes also explain the daytime peak and secondary nocturnal peak of CI occurrences in Fig. 12b. The prevalent daytime occurrences of CI on the coastal land were perhaps induced by strong surface heating (Fig. 13a), which generally resulted in subsequent afternoon rainfall there (Fig. 13b). The thermal contrast may also drive sea-breeze circulation, triggering the afternoon convection in the central and northern areas of Hainan Island (Zhu et al. 2017). In contrast, the early-morning peaks in $\mathrm{CI}$ and rainfall on windward coasts and in offshore areas were mainly due to the convergence of land breezes with onshore southerly monsoons or the effect of gravity waves (X. Chen et al. 2016, 2017; G. Chen et al. 2018; Du and Rotunno 2018). The convection development near midnight in the northwest Guangxi is usually attributed to the mountain-plain solenoid and diurnally varying low-level winds (G. Chen et al. 2012; Jiang et al. 2017). Overall, the CI occurrences exhibit good consistency with the observed rainfall in terms of spatial pattern and diurnal cycle, underscoring the reliability of the CI statistics from a physical perspective. 
(a) Cl peak hour

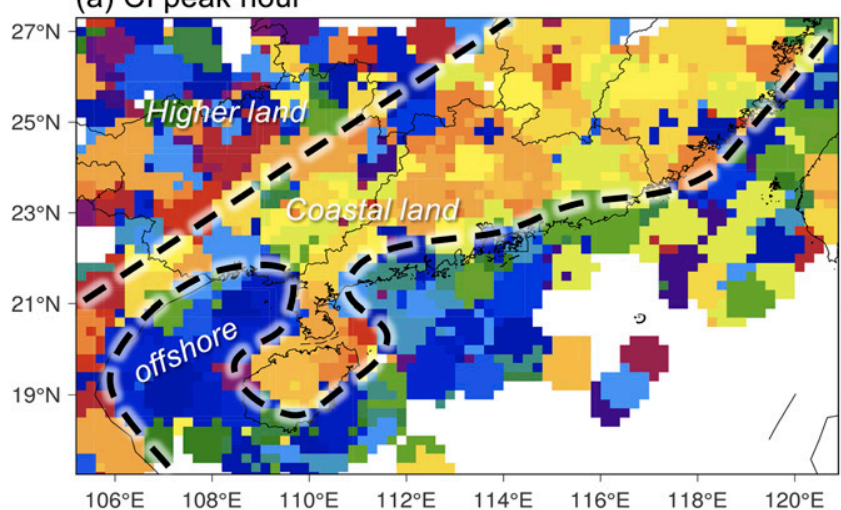

(b) Rainfall peak hour

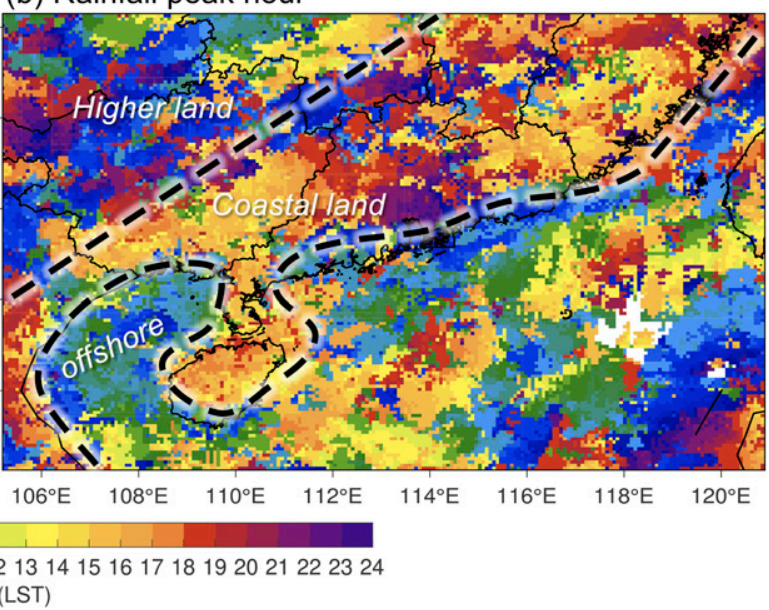

FIG. 13. (a) Peak hours of the identified CI events in June of 2017. The peak hour at any grid point is obtained by assigning the hour with the maximum number of $\mathrm{CI}$ occurrences within $50 \mathrm{~km}$. Before determining the peak hour, the number of CI occurrences at each hour is updated using the weighted three-point running average with weighting factors of $0.25,0.5$, and 0.25 , to avoid the possible dominance of one single hour. (b) Peak hour of the satellite-estimated rainfall in June of 2017.

\section{Summary and discussion}

In this study, the potential of applying quality-controlled radar mosaic maps to calculate the statistics of $\mathrm{CI}$ in China was demonstrated. A simple framework of objective CI identification by image processing was introduced. For the first time, the feasibility of using radar mosaic maps in China to generate a CI climatology was examined. The framework consists of three main parts: (i) extract the reflectivity data from radar mosaic maps after some quality-control procedures, (ii) locate all the convective cores and objectively identify CI events by applying CI algorithms to the first-occurrence convective cores, and (iii) quality check the identified CI events.

The framework was tested using radar mosaic maps over South China in June of 2017. There were 1286 CI events identified from a total of 7108 radar mosaic maps. The majority of CI occurrences were located at relatively flat areas or on the windward sides of mountains. Three hot spots of CI were located: the Pearl River delta, coastal zones of Guangxi and Guangdong, and Hainan Island. These hot spots were relatively robust because other two CI identification algorithms showed the similar patterns. Previous studies have suggested that the forcing responsible for rainfall over South China shifts from dynamically to thermodynamically dominated, from spring to summer. In June, both the thermally and dynamically driven convection is active over South China. In future studies, we should separate the two types of convection to discuss CI mechanisms.
The reliability of the identified CI events was confirmed in both direct and indirect ways. In the direct sense, all the identified CI events were manually checked by tracking the movement and duration of the precipitation echoes that corresponded to the CI cells. Only 5 of the 1286 identified CI cells were flagged as suspicious cases. In the indirect sense, the diurnal cycles and spatial patterns of the CI occurrences were compared with those of rainfall to ensure physical consistency. The diurnal cycle of CI occurrence coincides with that of rainfall estimates showing a major peak in the early afternoon and a secondary peak after midnight. The CI occurrence also exhibited late-night-to-morning peaks at the windward coasts and offshore, a noon-tolate-afternoon peak on the coastal land, and an eveningto-early-morning peak over the northwest highland. The three spatial modes were consistent with those of peak hours of rainfall. These results suggest that there was no visible noise or physical inconsistency for the identified $\mathrm{CI}$ events. Therefore, by the simple CI-detection framework through image processing, radar mosaic maps in China are now applicable for the study of CI climatology.

Our ongoing studies further use the framework to objectively identify CI events for a long period (from 2013 to 2019 and counting). The preliminary results show that a large sample size of CI occurrence can also be obtained in other warm-season months. This framework can also be applicable for contiguous China or other regions in which radar mosaic maps have fairly good data quality. Such long-term CI statistics will be of great help to understand the geographical and temporal characteristics of CI occurrences, especially to clarify 
how often convective storms are triggered at any given location. Discovering such a regional CI climate will further aid in studying the CI mechanisms under the circumstances of specific topographies, weather systems or regional climate. For instance, by summarizing long-period CI characteristics, the general relationship between CI and multiscale weather systems (monsoonal flows, sea-land breezes, LLJs, gravity waves, etc.) and local forcing (mountains, urbanization, etc.) can be extensively investigated, which may provide guidance for operational forecast ( $\mathrm{H}$. Wang et al. 2014; X. Chen et al. 2017; G. Chen et al. 2018; Du and Chen 2018, 2019; Du and Zhang 2019). In addition, the typical CI events or specific cases occurring in CI-active days can be identified from the CI database, which may further improve our understanding of the regional convective behavior.

With the recent advancement in computing capability and technology, we have now entered a new era of global convection-permitting NWP models (Zhang et al. 2019) and kilometer- and minute-resolution satellite observations (e.g., the GOES-R, Himawari-8, and Fengyun-4 satellites; Schmit et al. 2005; Bessho et al. 2016; Yang et al. 2017). A dataset of long-term CI statistics at a high spatiotemporal resolution will be a useful tool to evaluate the performance of convectionpermitting NWP models and to cross-examine the validity of satellite-based CI detection, thus further aiding in the improvement of severe weather nowcasting. The convection-permitting climatological simulations validated in high quality can also be helpful in studying the CI mechanism in any region where convection is frequently triggered.

Acknowledgments. The radar mosaic maps produced by the National Meteorological Center of CMA (http:// eng.nmc.cn/publish/radar/huanan.html) are gratefully acknowledged. The authors express thanks to the CPC of NOAA for providing the CMORPH data. Rain gauge data are offered by the CMA-Guangzhou Joint Research Center for Atmospheric Sciences with support from the Guangdong Meteorological Bureau. This work was supported by the National (Key) Basic Research and Development Program of China (Grant 2018YFC1507400), the National Natural Science Foundation of China (Grants 41905043, 41805035, and 41775094), and the Guangzhou Municipal Science and Technology Planning Project of China (Grant 201903010101). Details of the operational radar mosaics were supported by Lin Zhang (Meteorological Observation Center of CMA). Discussions with Chuntao Liu (Texas A\&M University), Qian Liu, and Yu Du (Sun Yat-sen University) on related subjects were beneficial. The code and some radar mosaic maps used in this study are available online (https://github.com/LanqiangBAI/CI_detection). Additional gratitude is extended to the three anonymous reviewers who have greatly aided in the improvement of this paper.

\section{REFERENCES}

Bai, L., 2013: Regional report on the current status of the exchange of weather radar data-RA II. Workshop on Radar Data Exchange, Exeter, United Kingdom, World Meteorological Organization, 3.1.2, https://www.wmo.int/pages/prog/ www/OSY/Meetings/ET-SBO_Workshop_Radar_Data_Ex/ SBO-WxR_Exchange_3.1.2_RAII_LiBai.pdf.

— Z. Meng, Y. Huang, Y. Zhang, S. Niu, and T. Su, 2019: Convection initiation resulting from the interaction between a quasi-stationary dryline and intersecting gust fronts: A case study. J. Geophys. Res., 124, 2379-2396, https://doi.org/10.1029/ 2018JD029832.

Banta, R. M., and C. B. Schaaf, 1987: Thunderstorm genesis zones in the Colorado Rocky Mountains as determined by traceback of geosynchronous satellite images. Mon. Wea. Rev., 115, 463-476, https://doi.org/10.1175/1520-0493(1987)115<0463: TGZITC $>2.0 . \mathrm{CO} ; 2$.

Bessho, K., and Coauthors, 2016: An introduction to Himawari-8/9Japan's new-generation geostationary meteorological satellites. J. Meteor. Soc. Japan, 94, 511-183, https://doi.org/ 10.2151/jmsj.2016-009.

Chen, G., W. Sha, and T. Iwasaki, 2009: Diurnal variation of precipitation over southeastern China: Spatial distribution and its seasonality. J. Geophys. Res., 114, D13103, https://doi.org/ 10.1029/2008JD011103.

,,,--- and K. Ueno, 2012: Diurnal variation of rainfall in the Yangtze River Valley during the spring-summer transition from TRMM measurements. J. Geophys. Res., 117, D06106, https://doi.org/10.1029/2011JD017056.

—, R. Lan, W. Zeng, H. Pan, and W. Li, 2018: Diurnal variations of rainfall in surface and satellite observations at the monsoon coast (South China). J. Climate, 31, 1703-1724, https://doi.org/ 10.1175/JCLI-D-17-0373.1.

Chen, M., Y. Wang, F. Gao, and X. Xiao, 2012: Diurnal variations in convective storm activity over contiguous North China during the warm season based on radar mosaic climatology. J. Geophys. Res., 117, D20115, https://doi.org/10.1029/ 2012JD018158.

Chen, X., K. Zhao, and M. Xue, 2014: Spatial and temporal characteristics of warm season convection over Pearl River Delta region, China, based on 3years of operational radar data. J. Geophys. Res. Atmos., 119, 12 447-12 465, https://doi.org/ 10.1002/2014JD021965.

_ $,-\ldots,-$, B. Zhou, X. Huang, and W. Xu, 2015: Radarobserved diurnal cycle and propagation of convection over the Pearl River Delta during Mei-Yu season. J. Geophys. Res. Atmos., 120, 12 557-12 575, https://doi.org/10.1002/ 2015JD023872.

, F. Zhang, and K. Zhao, 2016: Diurnal variations of the landsea breeze and its related precipitation over south China. J. Atmos. Sci., 73, 4793-4815, https://doi.org/10.1175/JAS-D-16-0106.1.

,,- , and,- 2017 : Influence of monsoonal wind speed and moisture content on intensity and diurnal variations of the mei-yu season coastal rainfall over South China. J. Atmos. Sci., 74, 2835-2856, https://doi.org/10.1175/JAS-D-17-0081.1. 
Cressman, G. P., 1959: An operational objective analysis system. Mon. Wea. Rev., 87, 367-374, https://doi.org/10.1175/1520-0493(1959) 087<0367:AOOAS >2.0.CO;2.

Dixon, M., and G. Wiener, 1993: TITAN: Thunderstorm Identification, Tracking, Analysis, and Nowcasting-A radar-based methodology. J. Atmos. Oceanic Technol., 10, 785-797, https://doi.org/ 10.1175/1520-0426(1993)010<0785:TTITAA $>2.0$. CO;2.

Du, Y., and G. Chen, 2018: Heavy rainfall associated with double low-level jets over southern China. Part I: Ensemble-based analysis. Mon. Wea. Rev., 146, 3827-3844, https://doi.org/10.1175/ MWR-D-18-0101.1.

— near the south coast of China. J. Atmos. Sci., 75, 2065-2082, https:// doi.org/10.1175/JAS-D-17-0397.1.

_ , and G. Chen, 2019: Heavy rainfall associated with double low-level jets over southern China. Part II: Convection initiation. Mon. Wea. Rev., 147, 543-565, https://doi.org/10.1175/MWR-D-18-0102.1.

-_ and F. Zhang, 2019: Banded convective activity associated with mesoscale gravity waves over Southern China. J. Geophys. Res. Atmos., 124, 1912-1930, https://doi.org/ 10.1029/2018JD029523.

Fabry, F., Q. Cazenave, and R. Basivi, 2013: Echo climatology, impact of cities, and initial convection studies: New horizons opened using 17 years of conterminous U.S. radar mosaics. 36th Conf. on Radar in Meteorology, Breckenridge, CO, Amer. Meteor. Soc., 10.1, https://ams.confex.com/ams/36Radar/webprogram/ Manuscript/Paper228783/EchoClimatoEtcRad36.pdf.

, V. Meunier, B. P. Treserras, A. Cournoyer, and B. Nelson, 2017: On the climatological use of radar data mosaics: Possibilities and challenges. Bull. Amer. Meteor. Soc., 98, 21352148, https://doi.org/10.1175/BAMS-D-15-00256.1.

Fu, Y., X. Pan, Y. Yang, F. Chen, and P. Liu, 2017: Climatological characteristics of summer precipitation over East Asia measured by TRMM PR: A review. J. Meteor. Res., 31, 142-159, https://doi.org/10.1007/s13351-017-6156-9.

Fulton, R. A., J. P. Breidenbach, D. Seo, D. A. Miller, and T. O’Bannon, 1998: The WSR-88D rainfall algorithm. Wea. Forecasting, 13,377-395, https://doi.org/10.1175/1520-0434(1998)013<0377: TWRA $>2.0 . \mathrm{CO} ; 2$.

Huang, L., and Y. Luo, 2017: Evaluation of quantitative precipitation forecasts by TIGGE ensembles for south China during the presummer rainy season. J. Geophys. Res., 122, 8494-8516, https://doi.org/10.1002/2017JD026512.

Huang, Y., Z. Meng, J. Li, W. Li, L. Bai, M. Zhang, and X. Wang, 2017: Distribution and variability of satellite-derived signals of isolated convection initiation events over central eastern China. J. Geophys. Res. Atmos., 122, 11357-11373, https://doi.org/ 10.1002/2017JD026946.

Jiang, Z., D.-L. Zhang, R. Xia, and T. Qian, 2017: Diurnal variations of presummer rainfall over southern China. J. Climate, 30, 755-773, https://doi.org/10.1175/JCLI-D-15-0666.1.

Joyce, R. J., J. E. Janowiak, P. A. Arkin, and P. Xie, 2004: CMORPH: A method that produces global precipitation estimates from passive microwave and infrared data at high spatial and temporal resolution. J. Hydrometeor., 5, 487-503, https://doi.org/10.1175/ 1525-7541(2004)005<0487:CAMTPG > 2.0.CO;2.

Keat, W., and Coauthors, 2019: Convective initiation and storm life-cycles in convection-permitting simulations of the Met Office Unified Model over South Africa. Quart. J. Roy. Meteor. Soc., 145, 1323-1336, https://doi.org/10.1002/QJ.3487.

Knight, C. A., and P. Squires, 1982: Hailstorms of the Central High Plains: The National Hail Research Experiment. Colorado Associated University Press, 82 pp.
Lock, N. A., and A. L. Houston, 2014: Empirical examination of the factors regulating thunderstorm initiation. Mon. Wea. Rev., 142, 240-258, https://doi.org/10.1175/MWR-D-13-00082.1.

Luo, Y., H. Wang, R. Zhang, W. Qian, and Z. Luo, 2013: Comparison of rainfall characteristics and convective properties of monsoon precipitation systems over South China and the Yangtze and Huai River basin. J. Climate, 26, 110-132, https:// doi.org/10.1175/JCLI-D-12-00100.1.

_ and Coauthors, 2017: The Southern China Monsoon Rainfall Experiment (SCMREX). Bull. Amer. Meteor. Soc., 98, 9991013, https://doi.org/10.1175/BAMS-D-15-00235.1.

Markowski, P. M., C. Hannon, and E. Rasmussen, 2006: Observations of convection initiation "failure" from the 12 June 2002 IHOP deployment. Mon. Wea. Rev., 134, 375-405, https:// doi.org/10.1175/MWR3059.1.

Meng, Z., D. Yan, and Y. Zhang, 2013: General features of squall lines in East China. Mon. Wea. Rev., 141, 1629-1647, https:// doi.org/10.1175/MWR-D-12-00208.1.

Nakatani, T., and Coauthors, 2015: Tokyo metropolitan area convection study for extreme weather resilient cities. Bull. Amer. Meteor. Soc., 96, ES123-ES126, https://doi.org/10.1175/ BAMS-D-14-00209.1.

Ohsawa, T., H. Ueda, T. Hayashi, A. Watanabe, and J. Matsumoto, 2001: Diurnal variations of convective activity and rainfall in tropical Asia. J. Meteor. Soc. Japan, 79, 333-352, https://doi.org/ 10.2151/jmsj.79.333.

Parker, M. D., and J. C. Knievel, 2005: Do meteorologists suppress thunderstorms?: Radar-derived statistics and the behavior of moist convection. Bull. Amer. Meteor. Soc., 86, 341-358, https:// doi.org/10.1175/BAMS-86-3-341.

Purdom, J. F. W., 1976: Some uses of high-resolution GOES imagery in the mesoscale forecasting of convection and its behavior. Mon. Wea. Rev., 104, 1474-1483, https://doi.org/ 10.1175/1520-0493(1976)104<1474:SUOHRG > 2.0.CO;2.

Reif, D. W., and H. B. Bluestein, 2017: A 20-year climatology of nocturnal convection initiation over the central and southern Great Plains during the warm season. Mon. Wea. Rev., 145, 1615-1639, https://doi.org/10.1175/MWR-D-16-0340.1.

Rickenbach, T. M., and S. A. Rutledge, 1998: Convection in TOGA COARE: Horizontal scale, morphology, and rainfall production. J. Atmos. Sci., 55, 2715-2729, https://doi.org/10.1175/ 1520-0469(1998)055<2715:CITCHS > 2.0.CO;2.

Schmit, T. J., M. M. Gunshor, W. P. Menzel, J. J. Gurka, J. Li, and A. S. Bachmeier, 2005: Introducing the next-generation Advanced Baseline Imager (ABI) on GOES-R. Bull. Amer. Meteor. Soc., 86, 1079-1096, https://doi.org/10.1175/ BAMS-86-8-1079.

Wang, H., Y. Luo, and B. Jou, 2014: Initiation, maintenance, and properties of convection in an extreme rainfall event during SCMREX: Observational analysis. J. Geophys. Res. Atmos., 119, 13 206-13 232, https://doi.org/10.1002/2014JD022339.

Wang, Y., L. Han, and H. Wang, 2014: Statistical characteristics of convective initiation in the Beijing-Tianjin region revealed by six-year radar data. J. Meteor. Res., 28, 1127-1136, https:// doi.org/10.1007/s13351-014-3061-3.

Weckwerth, T. M., and D. B. Parsons, 2006: A review of convection initiation and motivation for IHOP_2002. Mon. Wea. Rev., 134, 5-22, https://doi.org/10.1175/MWR3067.1.

_ J. W. Wilson, M. Hagen, T. J. Emerson, J. O. Pinto, D. L. Rife, and L. Grebe, 2011: Radar climatology of the COPS region. Quart. J. Roy. Meteor. Soc., 137, 31-41, https://doi.org/10.1002/qj.747. , J. Hanesiak, J. W. Wilson, S. B. Trier, S. K. Degelia, W. A. Gallus, R. D. Roberts, and X. Wang, 2019: Nocturnal convection 
initiation during PECAN 2015. Bull. Amer. Meteor. Soc., 100, 2223-2239, https://doi.org/10.1175/BAMS-D-18-0299.1.

Wilson, J. W., and W. E. Schreiber, 1986: Initiation of convective storms at radar-observed boundary-layer convergence lines. Mon. Wea. Rev., 114, 2516-2536, https://doi.org/10.1175/ 1520-0493(1986)114<2516:IOCSAR > 2.0.CO;2.

—, and R. D. Roberts, 2006: Summary of convective storm initiation and evolution during IHOP: Observational and modeling perspective. Mon. Wea. Rev., 134, 23-47, https://doi.org/ 10.1175/MWR3069.1.

Yang, J., Z. Zhang, C. Wei, F. Lu, and Q. Guo, 2017: Introducing the new generation of Chinese geostationary weather satellites, Fengyun-4. Bull. Amer. Meteor. Soc., 98, 1637-1658, https://doi.org/10.1175/BAMS-D-16-0065.1.

Yu, X., X. Yao, T. Xiong, X. Zhou, H. Wu, B. Deng, and Y. Song, 2006: The Principle and Application of Doppler Weather Radar (in Chinese). China Meteorological Press, 314 pp.
Zhang, F., Y. Qiang Sun, L. Magnusson, R. Buizza, S. Lin, J. Chen, and K. Emanuel, 2019: What is the predictability limit of midlatitude weather? J. Atmos. Sci., 76, 1077-1091, https:// doi.org/10.1175/JAS-D-18-0269.1.

Zhang, Q., X. Ni, and F. Zhang, 2017: Decreasing trend in severe weather occurrence over China during the past 50 years. Sci. Rep., 7 (1), 42310, https://doi.org/10.1038/ srep42310.

Zhu, L., Z. Meng, F. Zhang, and P. M. Markowski, 2017: The influence of sea- and land-breeze circulations on the diurnal variability in precipitation over a tropical island. Atmos. Chem. Phys., 17, 13 213-13 232, https://doi.org/10.5194/ acp-17-13213-2017.

Ziegler, C. L., and E. N. Rasmussen, 1998: The initiation of moist convection at the dryline: Forecasting issues from a case study perspective. Wea. Forecasting, 13, 1106-1131, https://doi.org/ 10.1175/1520-0434(1998)013<1106:TIOMCA > 2.0.CO;2. 